\title{
Type Building and Teaching Enlightenment of Domestic Fantasy Films since the $21^{\text {st }}$ Century
}

\author{
Yang Xin \\ Faculty of Liberal Arts, Northwest University, Xi'an 710127
}

Keywords: Fantasy film; High-concept film; Domestic genre film

\begin{abstract}
Fantasy films reflect the nature of life based on exaggerating and transforming the real world through allegories or legends. Domestic fantasy films have gradually adopted the high-concept model in recent years. Under market operations, these films become new favorites of the box office. It is urgent to consider how to make excellent domestic fantasy films and guide them to walk towards the international market based on combining the teaching practice and revelations of genre films. The most important thing is to balance the relations between the native country and the world. Apart from setting foot on national culture and local characteristics, a higher emphasis should be paid to humanistic expressions and endow them with more universal values.

Genre film is the product unique to the Hollywood film industry. Genre is a conventional and varying concept. ${ }^{[1]}$ With fixed plot models and characterization, genre films simplify the process of appreciating films. Additionally, some familiar film techniques are applied in the film appreciation process to enhance the audience's sense of joys. Generally speaking, fantasy films reflect the nature of life based on exaggerating and transforming the world through allegories or legends. Both sci-fi films and magical \& fantastic films fall in the category of fantasy films. The only difference is that the former upholds human technology and the latter believes in legends and mythologies. The difference mainly results from different cultural backgrounds. The fantasy film type is based on a fantastic space more superior than and exceeds the real space. It is the imitation of the fantasy world that differs from the real world. Apart from integrating the morals, etiquette and religious belief of the real world, it also meets the creator's fantasies about the reality. In the process of teaching genre films, the author found out students' interest in genre films are significantly higher than that of other films. Apparently, the fantastic world created by fantasy films has won great favor from young students through natural and casual expressions, intriguing plots, strongly expressive visual impact and extraordinary reality.

With constant development of film-making techniques in recent years, magical visual special effect has been one highlight of numerous fantastic films. Since then, the audience has been expecting more from film stories, but also fresh role setting and imitations of the fantastic world. What we have seen as of today are challenges brought by technological revolutions to films. The emergency of fantasy films is particularly obvious-The progress in film-making technology has brought huge changes.
\end{abstract}

\section{Characteristics—Fantastic Production under High-concept Model}

Nowadays, fantasy films are constantly learning from Western business models. Besides completely following industrialized procedures, fantasy films also adopt specialized production teams and internationalized special effect technology. In addition, there gradually form four business models of high-concept films, including huge investment, big production, large-scale marketing and large market. ${ }^{[2]}$ Peter Gump, president of Columbia Pictures, once said: "High concept is a narration means, which emphasizes concepts and contents are unique; in addition, the expression means should be highly explicit, making it easy for being expressed and understood ${ }^{[3]}$. On the one hand, appreciating high-concept films in class accelerates students' mastery of film appreciation experience. On the other hand, it facilitates students to master the production characteristics of such films. In recent years, high-concept films have exerted profound impact on Chinese film industry. To some extent, the characteristics of fantasy films meet the high-concept model. These films have significant characteristics, simple contents and accentuated plots, which make them easily 
understood and transmitted.

Domestic high-concept films are oriented on entertainment functions and aim to be commercial popular films that are focused on aesthetical factors. It is thus crucial for fantasy films to meet the appreciation habits of the public based on high-concept, especially those of young audience like college students. Domestic films have now entered the IP era. For Chinese traditional legends, they should not only be learned from and decomposed, but more importantly respected and reconstructed ${ }^{[4]}$. In recent years, domestic fantasy films have been featured with huge investment and large-scale production, targeting at the public that accept Chinese traditional legendary stories most easily. It is found out in teaching that students have natural interest in and profound love for such stories, which are highly dramatic and have easily-acceptable traditional values and world construction. By technical means, the story plots of legendary stories are artistic and appreciative. In addition, technical means bring sensory stimulations, making it easy to receive affirmation from the youth.

High-concept films have strict control of and requirements on colors and music. Music plays a crucial role in pre-phase marketing and post-phase promotion, making it a technique commonly applied in the market operations of Hollywood. A song not only complements film plots, but is more like the inner monologues of protagonists. From the perspective of images, high-concept film style aims to achieve visual spillover. Hence the style tone of fantasy films is unified and requires the support of an all-star casting to maximize the start effect of Hollywood. For this reason, the teaching of genre films is not only about images. Music appreciation and color identification are also elements that should be mastered by students in class.

The core of high-concept is that marketing determines production and designing marketing solutions in production. Market capacity and impetus are important components of high-concept films. For instance, Monster Hunt is a successful high-concept film model. The production is featured with an excellent team, flowing stories and a diversified world. In particular, Wuba, a lovely and kind monster, is greatly loved by the audience. The primary factor causing changes in the box office is the expansion of the middle-class ${ }^{[5]}$, which is also one of the elements helping the Monster Hunt to generate huge box revenues with the labels of fantasy and comedy. When economic and technical reforming theories are applied to commercial film production, such theories will play an unmatched role. The validity of basic principles behind such theories (namely which necessary means an enterprise adopts is to ensure the maximum long-term profits) is self-evident ${ }^{[6]}$. It can be concluded that domestic fantasy films need to orient on the effective guidance of market capacity driving, stylized characteristics and simple narrations under the high-concept production model, so as to represent the aesthetic characteristics of national style, digital production and visualization $^{[7]}$.

\section{Development-Combine Humane Care and Aesthetical Pursuits}

The film market has developed into a complete spatial construction. Nowadays, we can research the concept of the secondary space of content values inside film production. The commercial values or production values owned by films pursued in the primary space are elements owned by commercial films. Fantastic and grand visual packages, an all-star casting and splendid and exciting action scenes are important elements of fantastic commercial films. From the development perspective, domestic fantasy films lack the technical spirit of craftsman. At the commercial production level, the industrialized development, industrial production norms and industrial standardized cultivation of domestic fantastic films need further improvement. As the production standards of genre films are uneven, it is necessary to improve the commercial quality by combining and balancing pursing artistry and technology. Hence how to deepen students' understandings of the development status of fantasy films and produce domestic fantasy films that match international blockbusters are primary problems to be considered in teaching.

According to the plot trends of domestic fantasy films, domestic fantasy films still create fantastic worlds based on popular world views and rarely make breakthroughs at spiritual and philosophical levels. To seek new creation directions, fantasy films should jump out of current thinking patterns and apply anti-traditional and extraordinary means to creation or adopt richer 
expressions in forms and interest. In addition, richer expression means and methods should be added into the same type of description process to enrich audio-visual elements.

First of all, governmental cultural departments should expand current technical innovation platforms, increase opportunities for domestic and foreign communications and facilitate artistic and innovation mechanism. To do this, these departments should conduct technical improvement. The commercial films produced by the Hollywood have three magic weapons: capital, technology and market operation. Nowadays, domestic fantasy films have adequate capital and rely international team for technical production. Although domestic market operations have kept pace with international trends in recent years, there still lacks a complete market system. Additionally, the market supervision system should be completed to overcome emerged issues, including small scale and inadequate technical and professional accumulation of partial film-making companies in China. Apart from the joint cooperation between domestic creators and leaders, the cohesion of local market is also essential for fantasy films to have emotional and value resonance with fantasy films in the local culture and achieve success in the cross-cultural market.

Secondly, the most important aspect of breaking the current environmental shackle lies in the production of fantasy films. Fantasy is a means for people to master the world ${ }^{[8]}$. At present, domestic fantasy films remain in the magic and fantastic world and orient on Eastern value constructions. Furthermore, most stories are adapted from traditional classical literature. It is thus necessary to enhance students' accumulations of Chinese cultures and improve their reading taste of legendary books in class teaching. Taking the adaption of domestic film, The Journey to the West, for instance, has proved its unshakable status of ruling Chinese imaginations about gods and evils. Besides, the Classic of Mountains and Seas and Strange Stories from a Chinese Studio are also popular theme sources for fantasy stories.

Thirdly, fantasy films should pay attention to representing humane care based on pursuing rich contents. Good traditional images should be used to represent humane spirit. Moreover, bold imaginations should be combined with Chinese traditional elements. Besides reconstructing the narration modes and sign codes familiar to the audience, the types of films, production standards and creativity should be combined closely. To abstract value connotations and improve our aesthetical pursuits, our films should be based on the reality. For instance, The Mermaid, a blockbuster launched during the New Year movie season, made up a historical tradition about mermaids and introduced the story that humans brought severe destruction to the sea and ecology for money and desires. Although the film triggered great controversies due to its high revenues, director Stephen Chow was bold and creative to introduce environmental-protection themes into fantasy films. In addition, the abstract of value connotations requires films to pay attention to modern interpretation and value conveying behind magic images, rather than to replace sensory stimulations with artistic aesthetics to create wonders. Although fantasy films depict the worlds other than the human world, the human society are deeply implied.

\section{Enlightenment-Mutual Help between Teaching and Creation}

Foucault once said: "What is important is not the era of the told legend, but the era of telling the legend." The reason why The Journey to the West is adapted to films again and again is that the magic world creation and the promotion of Buddhist tenets actually include numerous social reality details of China. In The Principles of the Art of Education, German psychologist Hugo Münsterberg said: "There is only one way for you to know about a thing-separate it from everything else, so that your awareness is completely occupied by it and there is no space for anything else." ${ }^{[9]}$ In the creation and teaching of fantasy films, teachers should guide students to separate themselves from other works. Otherwise, similarity and repetitions are inevitable. Apart from carrying on traditions, teachers should encourage students to target their film concepts on locality, represent national characteristics and demonstrate cultural confidence. It is essential to avoid simple reference. By understanding and interpreting films, students may feel how Western fantasy films are devoted to creating dazzling visual impact and take active efforts to represent Western values and stands.

As domestic fantasy films keep breaking the records of box office, we can see the differences 
between domestic and foreign box offices. Nearly all the revenues of domestic fantasy films are from domestic audience. Conversely, the foreign market remains a hard nut to crack. It is partially caused by the differences between cultures and value orientations. As Chinese fantasy films are deficient in production technology and overseas transmission, the only way to make breakthroughs in the overseas market is to change the creation thinking and development modes of fantasy films. The genre film teaching for students majoring in Television and Film should not encourage telling stories without innovations, but need to seek new dialogues between traditional cultures and modern concepts through genre mixture and cultural integration. It is necessary to seize market trends to guide and improve teaching through practice. Nowadays, the teaching effect of Genre Film course in universities is far from ideal. This is partly caused by the lack of appropriate teaching methods for guiding teaching and pure theoretical explanations in class. As a new trial, comprehensive teaching combines script-writing, photography, post-phase production and promotion \& launch in teaching skillfully. Guided by this teaching method, the Genre Film course has its unique advantages: cultivate students' creation awareness, industrial awareness and market awareness.

Driven by the Internet wave, fantasy films combine realistic writing of the history and future realism. It should focus on the harmonious unification of art and technical progress. It is necessary for students to realize in Genre Film class that Chinese films should think about how to balance the relations between local regions and the world (story plot and theme significance) and between complexity and simplicity (narrating structure and aesthetics style) ${ }^{[10]}$. Both the literary origins of Western fantasy and the historical profundity of Eastern fantasy need to master the audience's real appreciation demands in the cross-regional participation of the audience. For this reason, fantasy films need philosophical reflections and humane expressions. In an environment with mature technology, only such creation methods can receive the understandings of universal values and real approval from the world.

\section{Reference}

[1] Dai Jinhua, Film Critics [M], Beijing: Peking University Press, 2015. P. 91

[2] Yin Hong,Wang Xiaofeng, Preliminary Explorations into High-concept Commercial Film Models [J], Contemporary Films, 2006 (3), P. 92-96

[3] Qiu Zhanghong, High-concept Film: Form, Style and Market [J], Film Art, 2011 (4), P. 132-138

[4] Ren Yan, Han Hongmei, Sensual Experience and Image Formation-Reflections Over Chinese New Fantasy Film Aesthetics in Recent Years [J], Contemporary Film, 2017 (9), P. 161

[5] Yang Yuanying, Overview on Films [M], China Film Press, 2010, P. 12-17

[6] Robert. C. Allen, Douglas Gomel, Film History: Theory and Practice [M], China Film Press, 2014, P. 181

[7] Zhang Yiwu, Rising of New Audience: New Space of Chinese Films [J], Contemporary Film, 2015 (12), P. 8-17

[8] Zhang Jiang, Rao Shuguang, Magic Narration Also Has Value Connotations [J], People's Daily, 2016 (7), P. 22-24

[9] Zhu Guangqian, Artistic Psychology [M], Shanghai: East China Normal University Press, 2015, P. 8

[10]Zhou Xuelin, High-concept Films and Domestic Blockbusters [J], Journal of Shanghai University (Social Science Edition), 2014 (02), P. 12-21 